Communication

\title{
Polycondensation of a Perylene Bisimide Derivative and L-Malic Acid as Water-Soluble Conjugates for Fluorescent Labeling of Live Mammalian Cells
}

\author{
Ji He ${ }^{1}$, Huixin Chen ${ }^{1}$, Yanjia Guo ${ }^{1}$, Liang Wang ${ }^{1, *}$, Lingli Zhu ${ }^{1}$, H. Enis Karahan ${ }^{2,+} \mathbb{D}^{\mathbb{D}}$ and \\ Yuan Chen ${ }^{3}$ (D) \\ 1 Tianjin Key Laboratory of Organic Solar Cells and Photochemical Conversion, School of Chemistry and \\ Chemical Engineering, Tianjin University of Technology, Tianjin 300384, China; heji0724@126.com (J.H.); \\ 13820608267@163.com (H.C.); hxhg19413@163.com (Y.G.); tjlghxhghj@163.com (L.Z.) \\ 2 School of Chemical and Biomedical Engineering, Nanyang Technological University, 62 Nanyang Drive, \\ Singapore 637459, Singapore; hekarahan@ntu.edu.sg \\ 3 School of Chemical and Biomolecular Engineering, The University of Sydney, Sydney 2006, Australia; \\ yuan.chen@sydney.edu.au \\ * Correspondence: wangliang@tjut.edu.cn; Tel.: +86-22-6021-4259 \\ + Current address: Singapore Membrane Technology Center (SMTC), Nanyang Environment and Water \\ Research Institute, Nanyang Technological University, Singapore 637141, Singapore
}

Received: 23 April 2018; Accepted: 22 May 2018; Published: 22 May 2018

\begin{abstract}
Based on simple mixing and polymerization of a hydroxyl-containing derivative of perylene bisimide (PBI) and L-malic acid, here, we demonstrate a new type of dye-polymer conjugate, PBI-poly $(\alpha, \beta$-malic acid) (PBI-PMA). Benefiting from the excellent water-solubility of weak polyanionic PMA structure and the high fluorescence of PBI, the PBI-PMA conjugates readily dissolve in water, displaying strong $\mathrm{pH}$-dependent fluorescence with the highest intensity at $\mathrm{pH} 6$. Due to the excellent biocompatibility of PMA, those conjugates showed low cytotoxicity on L929 cells. Using L929 and HeLa cells, we also confirmed that the PBI-PMA-labeled cells display intense fluorescence. Overall, the PBI-PMA conjugate demonstrates high potential as a cell labeling agent with its synthesis ease, good solubility in aqueous medium, low cytotoxicity, and high fluorescence.
\end{abstract}

Keywords: facile synthesis; perylene bisimide; poly( $\alpha, \beta$-malic acid); cell labeling; fluorescence

\section{Introduction}

Perylene bisimide (PBI) has high potential as a fluorescent label for cell staining thanks to its high fluorescence quantum yield, long band-gap, and good fluorescence stability [1-3]. However, the difficulty comes from the strong intermolecular $\pi-\pi$ interactions of PBIs' large aromatic core, which causes water insolubility [4,5]. Several studies have focused on introducing ionic groups or attaching water-soluble polymers to its bay or imide positions [6,7]. For example, Müllen et al. introduced ionic aromatic systems, such as phenoxy substituents with sulfuric acid residues, pyridinium salts, or quaternary ammonium salts, at its bay positions to suppress aggregation in water [8]. Wüerthner et al. targeted imide positions instead and synthesized water-soluble PBI derivatives with terminally linked polyglycerol dendrons [9]. Alternatively, Neoh et al. linked linear water-soluble polymers to PBI with poly[poly(ethylene glycol) methyl ether methacrylate] [10]. Our group also previously synthesized water-soluble PBI-incorporated polyurethanes [11]. Although those water-soluble PBIs have commonly demonstrated good solubility and fluorescence, their relatively tedious synthesis methods pose a disadvantage. Also, the 
water-soluble polymer systems so far tested are usually not biodegradable, or their degradation products are not totally safe.

$\operatorname{Poly}(\alpha, \beta$-malic acid) (PMA) is a polyester well-known with high water-solubility, biocompatibility, biodegradability, and bioresorbability [12,13]. Importantly, the final degradation product of PMA; i.e., L-malic acid, is an intermediary product of the tricarboxylic acid cycle of carbohydrate metabolism. In accordance, PMA and several PMA-based polymers have been reported in the form of hydrogels [14], tissue engineering scaffolds [15], and drug carriers [16] for biomedical applications. Although PMA is available from natural sources like bacteria, PMA polymers are mostly synthesized via the polycondensation method [17-19]. The polycondensation of PMA, based on the dehydration reaction between hydroxyl and carboxyl groups of L-malic acid, is a relatively simple chemistry. However, the ratio between hydroxyl and carboxyl groups in the malic acid is 1-to-2, which is a hindrance to obtaining high molecular weight PMA. Thus, introducing other compounds having two or more hydroxyl groups into the polycondensation system is beneficial for improving the molecular weight of PMA [20].

In this work, we conjugated PBI with PMA to improve PBI's water-solubility and biocompatibility. PBI-PMA polymers were synthesized via the polycondensation of $\mathrm{PBI}-\mathrm{OH}$ and L-malic acid. PBI-OH with two hydroxyl groups plays a dual role as both the fluorescence source and the polymer chain extender, while L-malic acid serves as the water-soluble segment. We showed that varying the PBI-OH content and reaction conditions (i.e., temperature and time) help to increase the average molecular weight of PBI-PMA. We further evaluated the applicability of PBI-PMA in biomedical applications as a fluorescent agent by a cellular toxicity test, MTT assay, and cell labeling experiments.

\section{Materials and Methods}

\subsection{Materials}

Perylene-3,4,9,10-tetracarboxylic dianhydride, diglycolamine, and L-malic acid were procured from Energy Chemical Co., Ltd. (Shanghai, China). Other reagents and all solvents were obtained from Tianjin Guangfu Fine Chemical Research Institute (Tianjin, China). Solvents were analytical grade, and all chemicals were used as received without further purification. $N, N^{\prime}$-bis(2-(2-hydroxyethoxy)ethyl) perylene-3,4,9,10-tetracarboxylic acid bisimide (PBI-OH) were synthesized following a previously reported method [21].

\subsection{Synthesis of PBI-PMA}

Ten different PBI-PMA samples were prepared in total as three groups varying PBI-OH feeding ratio (Group A), temperature (Group B), and time (Group C). A typical reaction procedure is as follows. First, $9.70 \mathrm{~g}$ of L-malic acid $(0.072 \mathrm{~mol})$ and $0.30 \mathrm{~g}$ of PBI-OH $(0.00053 \mathrm{~mol})$ were weighted in a reaction bottle and purged with pure $\mathrm{N}_{2}$ gas. Next, their mixture was stirred at $120{ }^{\circ} \mathrm{C}$ for $48 \mathrm{~h}$ under $\mathrm{N}_{2}$ atmosphere using vacuum $(1 \mathrm{~mm} / \mathrm{Hg})$ to remove water that forms during the polycondensation reaction. After dissolving the crude product in $30 \mathrm{~mL}$ of THF, the resulting mixture was first filtered through a short silica gel column to remove the unreacted PBI-OH, which is insoluble in THF. Then, solvent extraction was made by adding $100 \mathrm{~mL}$ diethyl ether and $100 \mathrm{~mL}$ petroleum ether on THF phase to remove excess monomer, L-malic acid. Obtained polymer precipitate was eventually dried under vacuum, yielding PB-PMA products with dark red color.

\subsection{Material Characterizations}

${ }^{1} \mathrm{H}$ nuclear magnetic resonance (NMR) spectra of synthesized polymer conjugates were recorded on a $400 \mathrm{MHz}$ NMR spectrometer (AV-400, Bruker, Bremen, Germany). To determine the molecular weight of the PBI- PMa Products, a gel permeation chromatography (GPC) system (Waters 2414, Waters, Milford, MA, USA) was employed. For GPC tests, $2.5 \mathrm{mg} / \mathrm{mL}$ PMA samples dissolved in tetrahydrofuran (THF) were used. And, the eluent flow rate and temperature of were set as $1.0 \mathrm{~mL} / \mathrm{min}$ 
and $35^{\circ} \mathrm{C}$, respectively. The optical properties of PBI-PMA were characterized in both organic solvent and water by ultraviolet/visible (UV/Vis) (Hitachi 3900, Tokyo, Japan) and fluorescence spectroscopies (Hitachi F4500).

\subsection{Cell Cytotoxicity Test}

L929 cells were employed as a cellular model for checking the mammalian cytotoxicity of PBI-PMA. Prior to the tests, the cell culture media supplemented with various PBI-PMA concentrations $\left(0.05,0.10,0.20,0.40,0.80,1.60\right.$, and $\left.3.20 \mathrm{mg} \cdot \mathrm{mL}^{-1}\right)$ were prepared. The $\mathrm{L} 929$ cells were then routinely cultured in 96-well plates with their initial density of $\sim 1 \times 10^{4}$ cells per well for $12 \mathrm{~h}$. Afterward, the medium in each well was replaced with the PBI-PMA-containing medium. The cells were further cultured in these media for another 24 or $48 \mathrm{~h}$. Following the protocol we have reported before [11], the cellular cytotoxicity test was then performed on each well by examining the reduction product of the MTT reagent (3-[4,5-dimethyl-thiazol-2-yl]-2,5-diphenyltetrazolium bromide). For the optical detection of formed formazan crystals, $560-\mathrm{nm}$ measurements were made on a multiplate reader (Tecan GENios, Bern, Switzerland). The cell viabilities for each PBI-PMA concentration was then calculated as the percentages relative to that obtained in the control group in which the cells were cultured without PBI-PMA. The two-sample $t$-test was used to analyze the data from PBI-PMA groups and the control group. The $p$-values less than $0.05(p<0.05)$ were considered statistically significant.

\subsection{Cell Labeling and Confocal Imaging}

For the cell labeling tests, L929 cells and HeLa cells were first cultured in glass-bottom plates for $24 \mathrm{~h}$. Then, the cells were subsequently cultured in PBI-PMA-containing media $\left(0.10 \mathrm{mg} \cdot \mathrm{mL}^{-1}\right)$ for another $40 \mathrm{~min}$. Then, the cells were washed three times with phosphate buffer saline ( $\mathrm{pH} 7.4)$ to remove the non-internalized dye-polymer conjugates remaining in media and loosely attached to the cellular membranes. Then, confocal laser scanning microscopy (CLSM) was studied to observe the labeled cells on a Nikon A1 microscope system (Tokyo, Japan).

\section{Results and Discussions}

\subsection{Synthesis of PBI-PMA}

PBI-PMA was synthesized by the co-polycondensation of L-malic acid and PBI-OH as shown in Scheme 1. Because of its poor solubility in polar environments, $\mathrm{PBI}-\mathrm{OH}$ cannot be dissolved totally in the melting L-malic acid at the beginning of the co-polycondensation process. Therefore, the mixture appeared as a reddish dispersion first. With the prolongation of the reaction for $10 \mathrm{~h}, \mathrm{PBI}-\mathrm{OH}$ gradually dissolved. And, a red homogeneous solution was obtained, which is mainly composed of the residual melt L-malic acid and the newly formed PBI-PMA. Importantly, PBI-OH with two hydroxyl groups did not induce extreme cross-linking in the resulting PBI-PMA samples. This observation may be attributed to the gradual dissolution and hence controlled feeding of $\mathrm{PBI}-\mathrm{OH}$ to the reaction media due to its poor solubility. All PBI-PMA samples were observed to be soluble in THF, and their molecular weight could be examined by GPC using THF as the eluent.

To obtain PBI-PMA with higher molecular weight, we studied the effect of three parameters, including the $\mathrm{PBI}-\mathrm{OH}$ feeding ratio, reaction temperature, and reaction time. The results are summarized in Table 1. When the PBI-OH feeding ratio was increased from 0 to $3 \mathrm{wt} \%$, the molecular weight of PBI-PMA products (Samples 1-A to 1-D) increased from 3.2 to $5.8 \mathrm{kDa}$. However, PBI-PMA's molecular weight did not increase further at the feeding ratio of $4 \mathrm{wt} \%$ (Sample 1-E). Comparing the Samples 1-A and 1-B, the addition of $1 \mathrm{wt} \% \mathrm{PBI}-\mathrm{OH}$ significantly improves the molecular weight from 3.2 to $4.8 \mathrm{kDa}$. Previous studies have shown that keeping the amount of hydroxyl and carboxyl functional groups equal is beneficial for obtaining polyesters with high molecular weight [22]. In this work, introducing PBI-OH with two hydroxyl groups into the polycondensation mixture with the carboxyl/hydroxyl ratio of $2 / 1$ helped to increase the proportion of reactive hydroxyl groups. 
The additional hydroxyl groups serve as the polymer-chain extender to react with the excess carboxyl groups, leading to the formation of PBI-PMA products higher in molecular weight. The reason behind observing similar molecular weights at 3 and $4 \mathrm{wt} \%$, on the other hand, presumably indicates reaching the solubility upper limit of PBI-OH in L-malic acid.

Table 1 also shows that the PBI-PMA production yield increases from 75 to $94 \%$ (Samples 2-A to 2-D) with the extension of reaction time from 12 to $60 \mathrm{~h}$. The highest molecular weight is observed at the reaction time of $48 \mathrm{~h}$. Furthermore, Samples 3-A, 1-D, and 3-C compare the effect of the reaction temperatures $\left(110,120\right.$ and $\left.130^{\circ} \mathrm{C}\right)$ on the molecular weight of PBI-PMA. Although the PBI-PMA production yield is higher at $130^{\circ} \mathrm{C}$, the molecular weight reaches the maximum of $5.8 \mathrm{kDa}$ at $120^{\circ} \mathrm{C}$. This outcome can be attributed to the fact that the polycondensation of PBI-PMA is a competitive reaction between the intermolecular and intramolecular dehydration of L-malic acid. While the intermolecular dehydration acts as positive reaction to produce PBI-PMA polymer, the side reaction reduces the molecular weight of PBI-PMA. And, important to note that the intramolecular dehydration of L-malic acid is even severer at high temperatures [23].

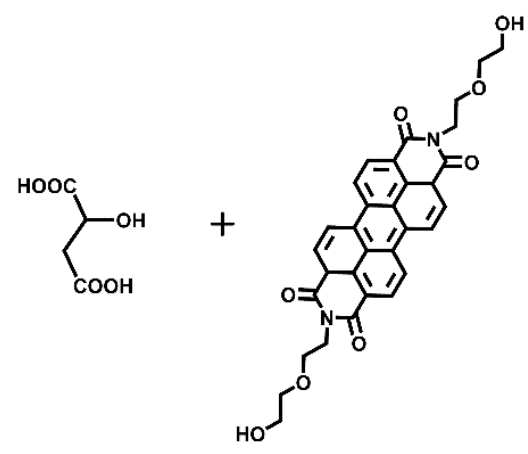

Malic acid

PBI-OH

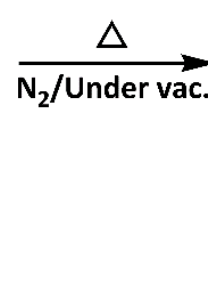

Scheme 1. Synth
structure shown
are expected to be
good solubility).

Table 1. Molecular weight, polydispersity index (PDI), and yield of PBI-PMA products synthesized varying reaction time, temperature, and $\mathrm{PBI}-\mathrm{OH}$ feeding content. (Note that the varied parameters in each experimental group are shown italicized).

\begin{tabular}{|c|c|c|c|c|c|c|c|}
\hline \multicolumn{2}{|c|}{ Sample } & \multirow{2}{*}{$\begin{array}{l}\text { PBI-OH Feeding } \\
\text { Ratio (wt \%) }\end{array}$} & \multirow{2}{*}{ Time (h) } & \multirow{2}{*}{$\begin{array}{l}\text { Temp. } \\
\left({ }^{\circ} \mathrm{C}\right)\end{array}$} & \multirow{2}{*}{ Mw (kDa) } & \multirow{2}{*}{$\begin{array}{c}\text { PDI } \\
\left(M_{\mathrm{w}} / M_{\mathrm{n}}\right)\end{array}$} & \multirow{2}{*}{ Yield (\%) } \\
\hline Group & Code & & & & & & \\
\hline \multirow{5}{*}{1} & $1-\mathrm{A}$ & 0 & 48 & 120 & 3.2 & 1.7 & 92 \\
\hline & $1-B$ & 1 & 48 & 120 & 4.8 & 2.1 & 93 \\
\hline & $1-\mathrm{C}$ & 2 & 48 & 120 & 5.1 & 2.0 & 92 \\
\hline & $1-\mathrm{D}^{1}$ & 3 & 48 & 120 & 5.8 & 2.2 & 90 \\
\hline & $1-\mathrm{E}$ & 4 & 48 & 120 & 5.8 & 1.9 & 90 \\
\hline \multirow{5}{*}{2} & $2-A$ & 3 & 12 & 120 & 1.2 & 1.3 & 75 \\
\hline & $2-B$ & 3 & 24 & 120 & 3.1 & 1.8 & 86 \\
\hline & $2-C$ & 3 & 36 & 120 & 4.9 & 2.0 & 89 \\
\hline & $1-\mathrm{D}^{1}$ & 3 & 48 & 120 & 5.8 & 2.2 & 90 \\
\hline & $2-\mathrm{D}$ & 3 & 60 & 120 & 5.5 & 2.2 & 94 \\
\hline \multirow{3}{*}{3} & $3-A$ & 3 & 48 & 110 & 5.3 & 2.1 & 89 \\
\hline & $1-\mathrm{D}^{1}$ & 3 & 48 & 120 & 5.8 & 2.2 & 90 \\
\hline & $3-B$ & 3 & 48 & 130 & 5.2 & 2.1 & 95 \\
\hline
\end{tabular}

${ }^{1}$ The Sample 1-D is shown in all three experimental groups as being the common condition. 
Since we wanted to test the performance of the sample with the highest molecular weight, we have considered selecting Samples 1-D or 1-E for further studies. Despite the lower PDI of Sample-E, we have selected Sample 1-D for further explorations due to its lower consumption of PBI-OH. As the first step, we have started with studying the chemical properties of Sample 1-D. Figure 1 shows the ${ }^{1} \mathrm{H} N M R$ spectrum of Sample 1-D. Two peaks at around $5.4 \mathrm{ppm}$ are attributed to the $\mathrm{CH}$ groups in the L-malic acid units. According to the literature [23], the peak at $5.5 \mathrm{ppm}$ is assigned to the $\alpha$-type L-malic acid unit, while the other peak at $5.3 \mathrm{ppm}$ indicates $\beta$-type. The two peaks at around $2.8 \mathrm{ppm}$ can be assigned to the $\mathrm{CH}_{2}$ groups in the L-malic acid unit. The signal related to perylene can also be observed at around $8.7 \mathrm{ppm}$ in the enlarged inset of Figure 1, which suggests the successful co-polycondensation of PBI-OH and L-malic acid. Calculated from the integration value of bands (1) and (3) in Figure 2, the PBI content in Sample 1-D is about $2.6 \mathrm{wt} \%$, indicating that over $85 \%$ of the PBI-OH precursors introduced have been polymerized with L-malic acid successfully.

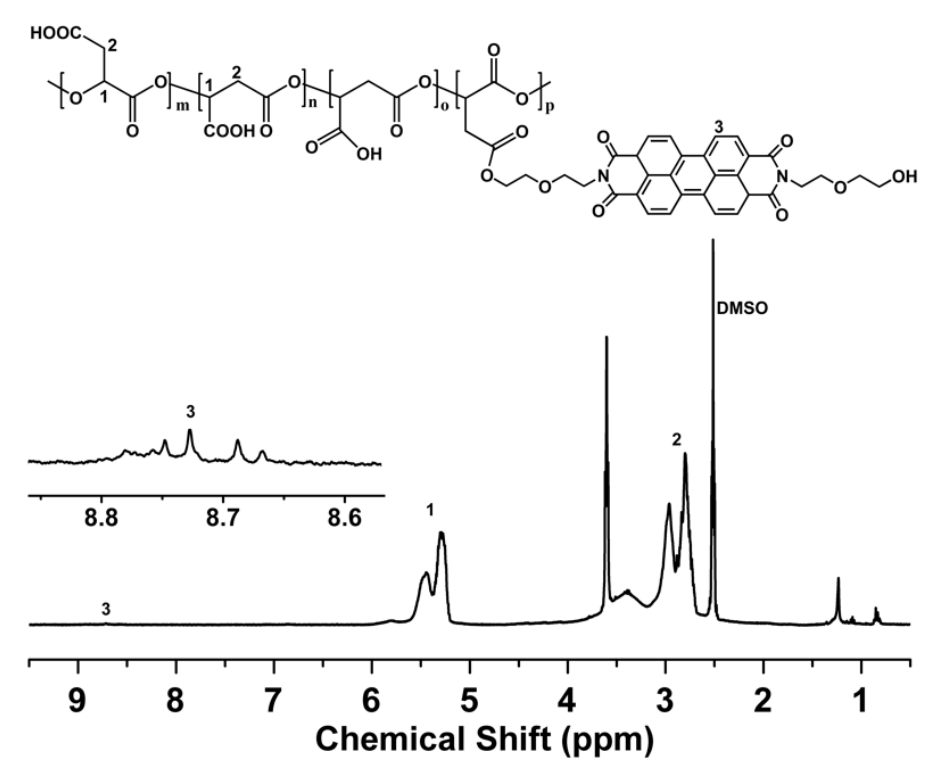

Figure 1. ${ }^{1} \mathrm{H}$ NMR spectrum of the PBI-PMA Sample 1-D. (Inset figure is the enlarged view of 8th main figure.)

\subsection{UV Absorbance and Fluorescence Properties of PBI-PMA}

Concentration-dependent UV/vis and fluorescence spectroscopies were used to study the spectroscopic properties of PBI-PMA in both THF and aqueous solutions. Figure 2a shows that the UV spectra of the PBI-PMA Sample 1-D in THF with its concentration ranging from 0.078 to $20 \mathrm{mg} \cdot \mathrm{mL}^{-1}$. There are three peaks at 521,486 , and $455 \mathrm{~nm}$, which are attributed to the $0-0,0-1$, and $0-2$ vibronic transitions, respectively [4,24]. The inset of Figure 2 a shows that the UV absorbance intensity increased linearly with the increase of polymer concentration. This observation indicates that the aggregation of PBI (through $\pi-\pi$ stacking interactions) has been effectively prevented by shielding the perylene cores from assembly via relatively high stereo-hindrance of the large PMA chains. The emission spectra (Figure 2b) presented two major peaks at 525 and $568 \mathrm{~nm}$ and one minor peak at around $620 \mathrm{~nm}$, which is in agreement with the previous studies [25,26]. In contrast to their UV spectra, the inset of Figure $2 \mathrm{~b}$ shows that the fluorescent intensity of PBI-PMA first increases linearly with the concentration from 0.078 to $5.0 \mathrm{mg} \cdot \mathrm{mL}^{-1}$, and then it shows a decreasing trend within the concentration range of 5.0 to $20 \mathrm{mg} \cdot \mathrm{mL}^{-1}$. At the same time, the fluorescence peak at $530 \mathrm{~nm}$ also shifts to $541 \mathrm{~nm}$ with the increase of the concentration to $20 \mathrm{mg} \cdot \mathrm{mL}^{-1}$. These results suggest fluorescence quenching and $\pi-\pi$ stacking of the perylene cores [4,24]. 
Next, we further studied the concentration-dependent UV/vis and fluorescence spectra of PBI-PMA in the aqueous phase. The results are presented in Figure $2 c, d$, respectively. Compared to their spectra in THF (organic solvent), the peak patterns shown in Figure $2 \mathrm{c}$ in the aqueous solution (Figure 2c) are quite different. The most intense absorption peak comes from the $0-1$ vibrational band at $498 \mathrm{~nm}$. The intensity of the $0-0$ absorption peak is reduced, and the peak is also slightly shifted towards the red region as the PBI-PMA concentration increased. Similar observations have been made in previous reports focused on the synthesis of some other water-soluble PBI derivatives such as oligomer-tethered PBI and PBI-incorporated poly(glyceryl acrylate) $[25,26]$. Although the PMA chain enables the water solubility of PBI-PMA, water is not as efficient as THF for dissolving the large aromatic ring of the perylene core. Thus, the aggregation tendency of the perylene cores should be higher in aqueous PBI-PMA than that in THF. The emission spectra given in Figure $2 \mathrm{~d}$ also show a similar trend as that observed from the PBI-PMA in THF solutions (Figure 2b). The intensity of their fluorescence peaks first increases when the concentration is below $1.25 \mathrm{mg} \cdot \mathrm{mL}^{-1}$ and then decreases as the concentration further increasing from 1.25 to $20 \mathrm{mg} \cdot \mathrm{mL}^{-1}$ (Figure $2 \mathrm{~d}$ inset). Notably, the turning point of fluorescent intensity is at $1.25 \mathrm{mg} \cdot \mathrm{mL}^{-1}$, which is much lower than the value obtained in the THF solution $\left(5 \mathrm{mg} \cdot \mathrm{mL}^{-1}\right)$. This observation also suggests that more aggregation of the perylene cores occurred in water than THF.
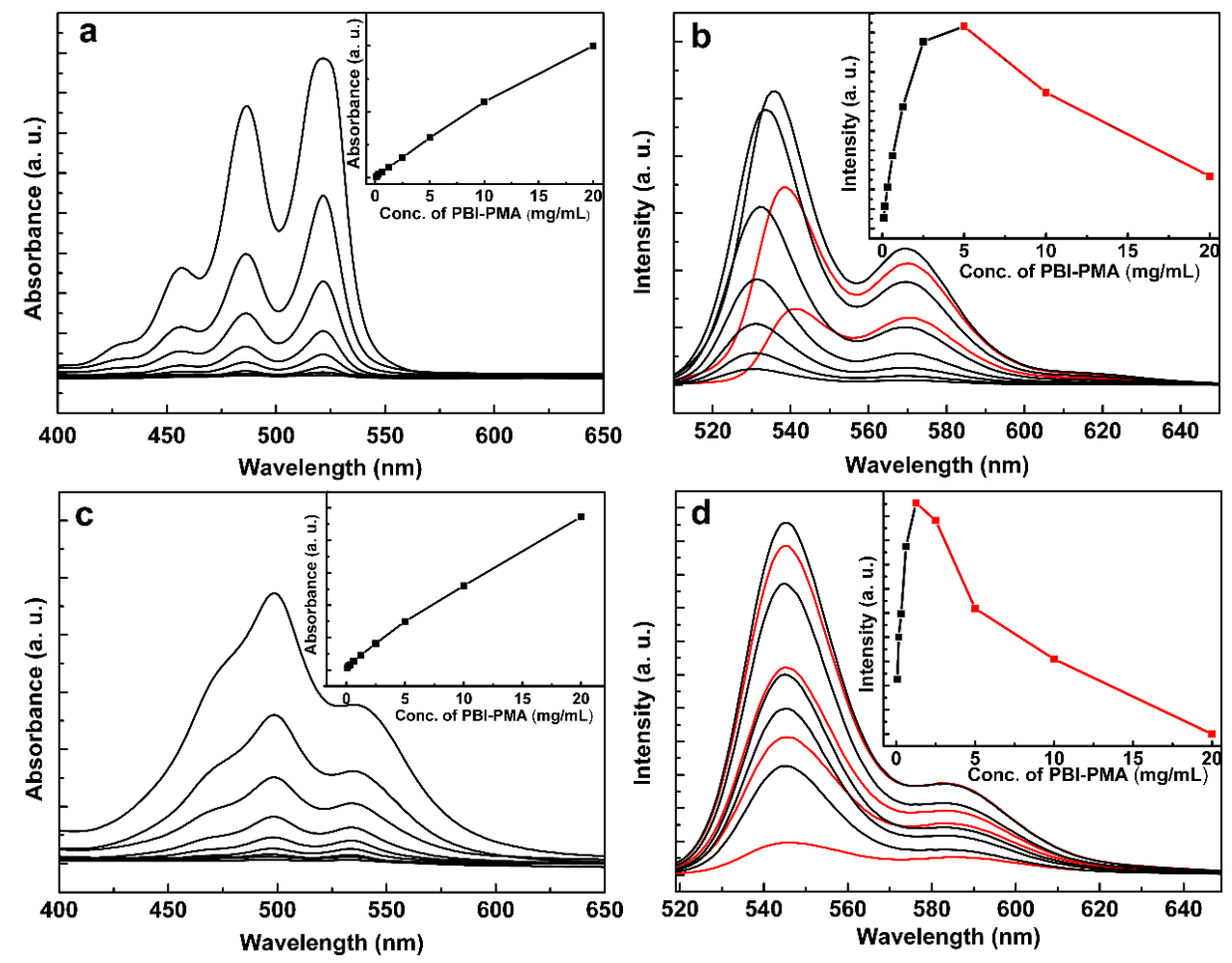

Figure 2. Optical properties of PBI-PMA: (a) UV/vis absorption spectra of PBI-PMA in tetrahydrofuran (THF); (b) Fluorescence spectra of PBI-PMA in THF; (c) UV/vis absorption spectra of PBI-PMA in water; (d) Fluorescence spectra of PBI-PMA in water. For all characterizations, the concentrations of PBI-PMA samples are parallel and ranged from 0.78 to $20 \mathrm{mg} \cdot \mathrm{mL}^{-1}$.

\subsection{Ph-Dependent Fluorescence of PBI-PMA}

PMA with abundant carboxyl groups can be considered as a weak polyanion with $\mathrm{pH}$-dependent solubility in water $[27,28]$. Therefore, it is useful to study the $\mathrm{pH}$ sensitivity of the fluorescence behavior of PBI-PMA before the cell labeling tests. Figure 3 shows the fluorescence spectra of Sample 1-D at the concentration of $1.25 \mathrm{mg} \cdot \mathrm{mL}^{-1}$ in several buffer conditions with $\mathrm{pH}$ values ranging from 3.3 to 8.0 (Figure 3). The fluorescence intensity of Sample 1-D increases with the increase of the $\mathrm{pH}$ until the $\mathrm{pH}$ 
reaches 6.0, and then decreases at higher $\mathrm{pH}$ values (pH 7 and 8). Besides, the fluorescence spectrum at $\mathrm{pH} 8$ also exhibits a significant red shift. The high degree of ionization of the carboxyl groups in PBI-PMA can improve its solubility, which might explain the observed fluorescence intensity rise at the $\mathrm{pH}$ from 3.3 to 6.0. However, the main component of PBI-PMA, PMA, contains ester groups, which are prone to degradation in aqueous solutions (hydrolysis). And, the degradation of PBI-PMA can be auto-catalyzed by its own carboxyl groups [29]. Further, as we have confirmed with GPC measurements (Supplementary Materials Figure S1), the PBI-PMA degrades significantly at pH 8, which leads to the lower solubility and lower fluorescence intensity of PBI. Overall, the Sample 1-D shows relatively higher fluorescence intensity at $\mathrm{pH} 6$ and 7. The cytoplasmic $\mathrm{pH}$ of healthy and cancerous human cells mostly vary around $\mathrm{pH} 7.0-7.5$ and 6.0-7.0, respectively. Since $\mathrm{pH} 6$ and 7 are pretty close to the cytoplasmic $\mathrm{pH}$ of cancerous and normal mammalian cells [30,31], the PBI-PMA can be expected to work for a wide range of cell types.

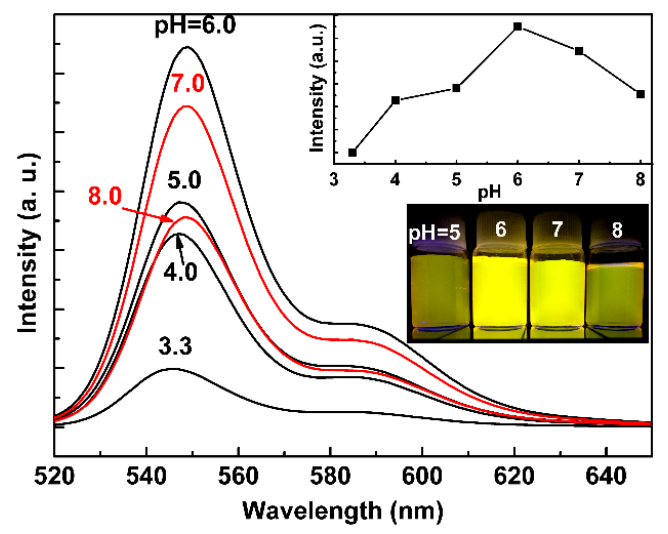

Figure 3. Fluorescence spectra of the PBI-PMA Sample 1-D in the buffers with various $\mathrm{pH}$ values with its concentration being $1.25 \mathrm{mg} \cdot \mathrm{mL}^{-1}$. (Excitation wavelength is $488 \mathrm{~nm}$. The inset graph and image show the peak maxima of the curves as a function of $\mathrm{pH}$ and the photography of samples excited by UV lamp).

\subsection{Cytotoxicity and Cell Labeling}

Before the cell labeling tests, the cytotoxicity of PBI-PMA should be evaluated. To this end, L929 cells were incubated in the media containing $0.05,0.10,0.20,0.40,0.80,1.60$, and $3.20 \mathrm{mg} \cdot \mathrm{mL}^{-1}$ of PBI-PMA for 24 and $48 \mathrm{~h}$, respectively, and then each of the samples were examined by MTT assay. (The results are shown in Supplementary Materials Figure S2.) After $24 \mathrm{~h}$ incubation, a negative correlation was found between the cell viability and the polymer concentration. In detail, as the concentration increases from 0.05 to $3.2 \mathrm{mg} \cdot \mathrm{mL}^{-1}$, the viability of L929 cells is reduced from 97.8 to $70.5 \%$. A similar trend is observed after $48 \mathrm{~h}$ of incubation. The cellular viabilities are all above $60 \%$, which suggests that most of the cells can sustain their normal metabolic activities after being exposed to the Sample 1-D. The low cytotoxicity can be ascribed to the high content of biocompatible PMA in PMA-PBI conjugates. Water-soluble PMA can also effectively prevent perylene dyes to interact with proteins nonspecifically, shielding the perylene dyes directly attaching with cells and in turn reducing the toxicity of PBI-PMA polymer [32]. Supplementary Materials Figure S2 also shows that the cell viabilities after the 48-h incubation are mostly higher than those after the 24-h incubation. This phenomenon is more notable at the higher concentrations of $0.80,1.60$ and $3.20 \mathrm{mg} \cdot \mathrm{mL}^{-1}$. When the incubation time is extended, PMA segments in PBI-PMA may degrade to produce L-malic acid and other oligomers, which can be absorbed and metabolized by cells. This would cause a decrease in the concentration of PBI-PMA in the cell culture media, thus lower the toxicity of high concentration of PBI-PMA in time. 
L929 and HeLa cells were used as models of normal and cancerous mammalian tissues, respectively. For both models, the cells were allowed to endocytose Sample 1-D PPBI-PMA found in growth media $\left(0.10 \mathrm{mg} \cdot \mathrm{mL}^{-1}\right)$ for $40 \mathrm{~min}$. Then, the brightfield and fluorescence images were taken under the CLSM by focusing at the nuclei of the two cell types. The brightfield images shown in the left column of Figure 4 show expected cellular morphologies, indicating that most of the cells grow well in the media containing PBI-PMA. Strong green fluorescence emitted from the cells shown in the middle column in Figure 4 indicate the fluorescent labeling was successful. The merged images (right column) show that the emission is mainly from the cytoplasm and the area related to cellular nuclei is dark. This observation suggests that the internalized PBI-PMA conjugates accumulate in the cellular cytoplasm but cannot penetrate the nuclei. Also, it is crucial to emphasize that the observation of cell nuclei (as dark spots) in the middle column of Figure 4 can be viewed as an indication of the collection of CLSM images from the middle sections of the cells mostly. In addition, some cells with double nuclei were observed as indicated by arrows in Figure 4. This observation suggests that the cells are still able to divide after the PBI-PMA labeling, which further coincides with the MTT assay results showing low toxicity.

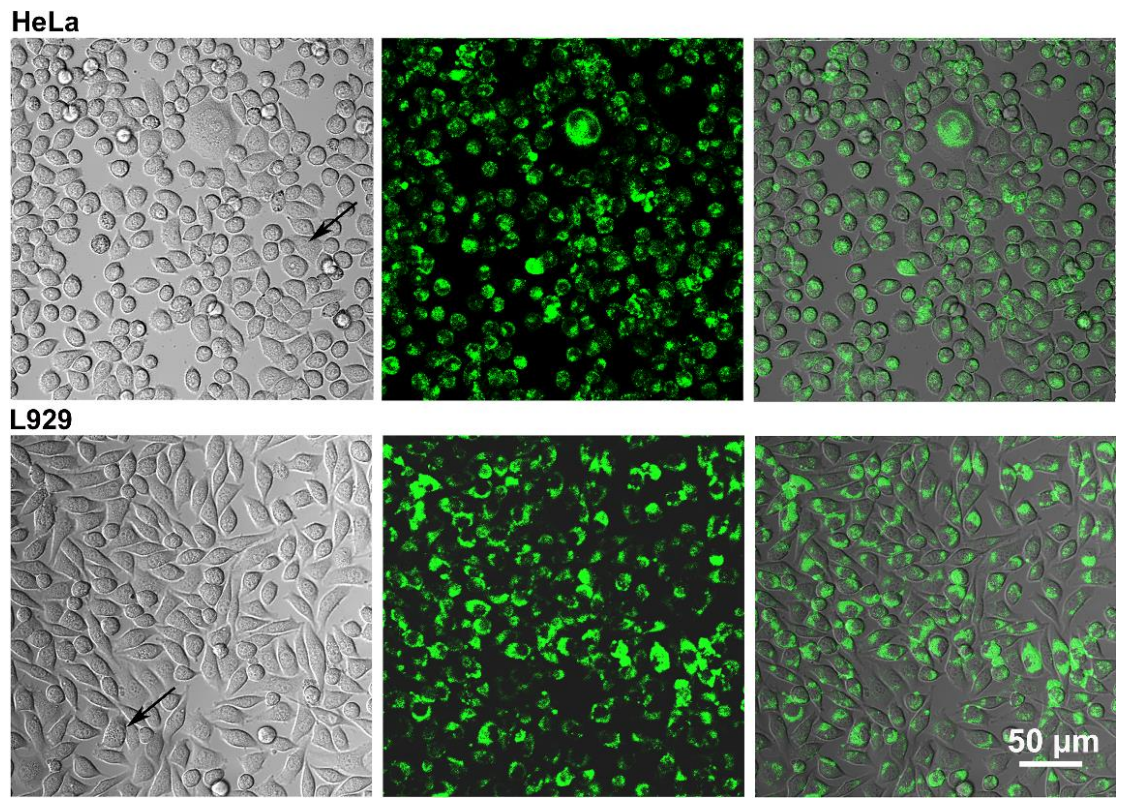

Figure 4. Confocal laser scanning microscopy CLSM images of L929 and HeLa cells stained by $0.10 \mathrm{mg} \cdot \mathrm{mL}^{-1}$ PBI-PMA medium for $40 \mathrm{~min}$. (Excitation wavelength is the same as used for fluorescence spectroscopy experiments summarized in Figure 3, $488 \mathrm{~nm}$. All figures share the same scale bar given in bottom right image).

\section{Conclusions}

Insoluble PBI was successfully incorporated into biodegradable PMA via a facile one-step polycondensation reaction. To our knowledge, the PBI-OH has been employed as a polymer chain extender and fluorophore for the first time in this study. The synthesis of PBI-PMA was optimized to obtain higher molecular weight and yield. We found that introducing $3 \mathrm{wt} \% \mathrm{PBI}-\mathrm{OH}$ and performing the reaction at $120{ }^{\circ} \mathrm{C}$ for $48 \mathrm{~h}$ gives the optimum results, providing PBI-PMA products with the molecular weight value of around $5.8 \mathrm{kDa}$. PBI-PMA can easily dissolve in water and shows typical UV absorption and fluorescence emission behavior of perylene-based dyes. The fluorescence intensity of PBI-PMA solution is $\mathrm{pH}$-dependent with the strongest fluorescence when the $\mathrm{pH}$ is around six, which is a physiologically acceptable condition for both healthy and normal human cells. Further, PBI-PMA shows low toxicity towards L929 cells in the MTT cell viability assay. We have also confirmed 
the utility of PBI-PMA as fluorescent labels using both L929 and HeLa cell lines. The PBI-PMA-labeled cells not only emitted strong green fluorescence from their cytoplasm but also showed some features of growth morphology. Our results demonstrate that PBI-PMA is a promising cell labeling agent with good water solubility, high fluorescence, and biocompatibility. We plan to benchmark the performance of PBI-PMA with different PBI solubilization strategies in future work.

Supplementary Materials: The following are available online at http:/ /www.mdpi.com/2073-4360/10/5/559/s1, Figure S1: GPC analysis of PBI-PMA incubated in PBS for $10 \mathrm{~min}$ at $\mathrm{pH} 6$ and 8, respectively; Figure S2: Viability of L929 cells incubated in the media containing $0.05,0.10,0.20,0.40,0.80,1.60$, and $3.20 \mathrm{mg} \cdot \mathrm{mL}^{-1}$ of PBI-PMA for 24 and $48 \mathrm{~h}$.

Author Contributions: L.W. and Y.C. conceived the study and designed the experiments; J.H., H.C., Y.G. and L.Z. performed the experimental work; L.W. analyzed the data; all authors discussed the results; L.W. and H.E.K. co-wrote, and Y.C. edited the manuscript; all authors approved the submitted paper.

Funding: This research was funded by the National Natural Science Foundation of China Projects (51143003 and 51203116), the Natural Science Foundation of Tianjin, China (12JCQNJC02000) and the National Training Programs of Innovation and Entrepreneurship for Undergraduates of China. Y.C. acknowledges financial support from the Australian Research Council under the Future Fellowships scheme (FT160100107) and the Discovery Project (DP180102210).

Conflicts of Interest: The authors declare no conflict of interest.

\section{References}

1. Kaloyanova, S.; Zagranyarski, Y.; Ritz, S.; Hanulová, M.; Koynov, K.; Vonderheit, A.; Müllen, K.; Peneva, K. Water-Soluble NIR-Absorbing Rylene Chromophores for Selective Staining of Cellular Organelles. J. Am. Chem. Soc. 2016, 138, 2881-2884. [CrossRef] [PubMed]

2. Huth, K.; Heek, T.; Achazi, K.; Kühne, C.; Urner, L.H.; Pagel, K.; Dernedde, J.; Haag, R. Noncharged and Charged Monodendronised Perylene Bisimides as Highly Fluorescent Labels and their Bioconjugates. Chem. Eur. J. 2017, 23, 4849-4862. [CrossRef] [PubMed]

3. Muthuraj, B.; Mukherjee, S.; Chowdhury, S.R.; Patra, C.R.; Iyer, P.K. An efficient strategy to assemble water soluble histidine-perylene diimide and graphene oxide for the detection of PPi in physiological conditions and in vitro. Biosens. Bioelectron. 2017, 89, 636-644. [CrossRef] [PubMed]

4. Görl, D.; Zhang, X.; Würthner, F. Molecular assemblies of perylene bisimide dyes in water. Angew. Chem. Int. Ed. 2012, 51, 6328-6348. [CrossRef] [PubMed]

5. Zhu, L.; Wu, W.; Zhu, M.Q.; Han, J.J.; Hurst, J.K.; Li, A.D.Q. Reversibly photoswitchable dual-color fluorescent nanoparticles as new tools for live-cell imaging. J. Am. Chem. Soc. 2007, 129, 3524-3526. [CrossRef] [PubMed]

6. Tan, H.; Liu, H.; Liu, Y.; Duan, W.; Yi, X.; Wu, Y.; Zhao, H.; Bai, L. A novel water-soluble fluorescent polymer based on perylene bisimides dyes: One-pot preparation and its bio-imaging. J. Biomater. Sci. Polym. Ed. 2016, 27, 455-471. [CrossRef] [PubMed]

7. Yang, Y.; He, P.; Wang, Y.; Bai, H.; Wang, S.; Xu, J.F.; Zhang, X. Supramolecular Radical Anions Triggered by Bacteria In Situ for Selective Photothermal Therapy. Angew. Chem. Int. Ed. 2017, 56, 16239-16242. [CrossRef] [PubMed]

8. Kohl, C.; Weil, T.; Qu, J.; Müllen, K. Towards highly fluorescent and water-soluble perylene dyes. Chem. Eur. J. 2004, 10, 5297-5310. [CrossRef] [PubMed]

9. Heek, T.; Fasting, C.; Rest, C.; Zhang, X.; Würthner, F.; Haag, R. Highly fluorescent water-soluble polyglycerol-dendronized perylene bisimide dyes. Chem. Commun. 2010, 46, 1884-1886. [CrossRef] [PubMed]

10. Wang, L.; Xu, L.; Neoh, K.G.; Kang, E.-T. Water-soluble highly fluorescent poly[poly(ethylene glycol) methyl ether methacrylate] for cell labeling. J. Mater. Chem. 2011, 21, 6502-6505. [CrossRef]

11. Wang, L.; Sun, C.; Li, S.; Jia, N.; Li, J.; Qu, F.; Goh, K.; Chen, Y. Perylene bisimide-incorporated water-soluble polyurethanes for living cell fluorescence labeling. Polymer 2016, 82, 172-180. [CrossRef]

12. Chi, Z.; Liu, G.L.; Liu, C.G.; Chi, Z.M. Poly( $\beta$-L-malic acid) (PMLA) from Aureobasidium spp. and its current proceedings. Appl. Microbiol. Biotechnol. 2016, 100, 3841-3851. [CrossRef] [PubMed]

13. Osanai, S.; Nakamura, K. Effects of complexation between liposome and poly(malic acid) on aggregation and leakage behaviour. Biomaterials 2000, 21, 867-876. [CrossRef] 
14. He, B.; Zeng, J.; Nie, Y.; Ji, L.; Wang, R.; Li, Y.; Wu, Y.; Li, L.; Wang, G.; Luo, X.; et al. In situ gelation of supramolecular hydrogel for anti-tumor drug delivery. Macromol. Biosci. 2009, 9, 1169-1175. [CrossRef] [PubMed]

15. Qian, J.; Xu, W.; Zhang, W.; Jin, X. Preparation and characterization of biomorphic poly(L-lactide-co- $\beta$-malic acid) scaffolds. Mater. Lett. 2014, 124, 313-317. [CrossRef]

16. Venkatraj, N.; Nanjan, M.J.; Loyer, P.; Chandrasekar, M.J.N.; Cammas Marion, S. Poly(malic acid) bearing Doxorubicin and N-Acetyl Galactosamine as a site-specific prodrug for targeting hepatocellular carcinoma. J. Biomater. Sci. Polym. Ed. 2017, 28, 1140-1157. [CrossRef] [PubMed]

17. Xia, J.; Li, R.; He, A.; Xu, J.; Liu, X.; Li, X.; Xu, J. Production of poly( $\beta$-L-malic acid) by Aureobasidium pullulans HA-4D under solid-state fermentation. Bioresour. Technol. 2017, 244, 289-295. [CrossRef] [PubMed]

18. Belibel, R.; Barbaud, C. Synthesis and characterizations of hemiditactic homopolymers derived of poly(3-allyl-3-methylmalic acid): An example of a new class of polymer's ditacticity. J. Polym. Sci. A 2017, 55, 2408-2418. [CrossRef]

19. Anil Kumar, P.K.; Shamala, T.R.; Kshama, L.; Prakash, M.H.; Joshi, G.J.; Chandrashekar, A.; Latha Kumari, K.S.; Divyashree, M.S. Bacterial synthesis of poly(hydroxybutyrate-co-hydroxyvalerate) using carbohydrate-rich mahua (Madhuca sp.) flowers. J. Appl. Microbiol. 2007, 103, 204-209. [CrossRef] [PubMed]

20. Telegdi, J.; Trif, L.; Mihály, J.; Nagy, E.; Nyikos, L. Controlled synthesis and characterization of biodegradable, stereomer co-polycondensates of L-malic acid. J. Therm. Anal. Calorim. 2015, 121, 663-673. [CrossRef]

21. Ustinov, A.V.; Dubnyakova, V.V.; Korshun, V.A. A convenient "click chemistry" approach to perylene diimide-oligonucleotide conjugates. Tetrahedron 2008, 64, 1467-1473. [CrossRef]

22. Hyon, S.H.; Jamshidi, K.; Ikada, Y. Synthesis of polylactides with different molecular weights. Biomaterials 1997, 18, 1503-1508. [CrossRef]

23. Kajiyama, T.; Kobayashi, H.; Taguchi, T.; Kataoka, K.; Tanaka, J. Improved synthesis with high yield and increased molecular weight of poly $(\alpha, \beta$-malic acid) by direct polycondensation. Biomacromolecules 2004, 5 , 169-174. [CrossRef] [PubMed]

24. Sun, M.; Müllen, K.; Yin, M. Water-soluble perylenediimides: Design concepts and biological applications. Chem. Soc. Rev. 2016, 45, 1513-1528. [CrossRef] [PubMed]

25. Samudrala, R.; Zhang, X.; Wadkins, R.M.; Mattern, D.L. Synthesis of a non-cationic, water-soluble perylenetetracarboxylic diimide and its interactions with G-quadruplex-forming DNA. Bioorgan. Med. Chem. 2007, 15, 186-193. [CrossRef] [PubMed]

26. Xu, L.Q.; Wang, L.; Zhang, B.; Lim, C.H.; Chen, Y.; Neoh, K.G.; Kang, E.T.; Fu, G.D. Functionalization of reduced graphene oxide nanosheets via stacking interactions with the fluorescent and water-soluble perylene bisimide-containing polymers. Polymer 2011, 52, 2376-2383. [CrossRef]

27. Felber, A.E.; Dufresne, M.H.; Leroux, J.C. PH-sensitive vesicles, polymeric micelles, and nanospheres prepared with polycarboxylates. Adv. Drug Deliv. Rev. 2012, 64, 979-992. [CrossRef] [PubMed]

28. Lu, C.; Mu, B.; Liu, P. Stimuli-responsive multilayer chitosan hollow microspheres via layer-by-layer assembly. Colloids Surf. B 2011, 83, 254-259. [CrossRef] [PubMed]

29. Yang, J.; Cao, X.; Zhao, Y.; Wang, L.; Liu, B.; Jia, J.; Liang, H.; Chen, M. Enhanced pH stability, cell viability and reduced degradation rate of poly(L-lactide)-based composite in vitro: Effect of modified magnesium oxide nanoparticles. J. Biomater. Sci. Polym. Ed. 2017, 28, 486-503. [CrossRef] [PubMed]

30. Casey, J.R.; Grinstein, S.; Orlowski, J. Sensors and regulators of intracellular pH. Nat. Rev. Mol. Cell Biol. 2010, 11, 50-61. [CrossRef] [PubMed]

31. Hou, H.; Zhao, Y.; Li, C.; Wang, M.; Xu, X.; Jin, Y. Single-cell pH imaging and detection for $\mathrm{pH}$ profiling and label-free rapid identification of cancer-cells. Sci. Rep. 2017, 7, 1759. [CrossRef] [PubMed]

32. Zhao, Z.; He, M.; Yin, L.; Bao, J.; Shi, L.; Wang, B.; Tang, C.; Yin, C. Biodegradable nanoparticles based on linoleic acid and poly $(\beta$-malic acid $)$ double grafted chitosan derivatives as carriers of anticancer drugs. Biomacromolecules 2009, 10, 565-572. [CrossRef] [PubMed]

(C) 2018 by the authors. Licensee MDPI, Basel, Switzerland. This article is an open access article distributed under the terms and conditions of the Creative Commons Attribution (CC BY) license (http:/ / creativecommons.org/licenses/by/4.0/). 